\title{
Scale of Positive and Negative Affect: Validation of PNA-10 in Chilean Youth
}

Karla Tay-Karapas 1-2 \& Sagrario Yárnoz-Yaben 2

Catholic University of the North (Chile) 1 - University of the Basque Country (Spain) 2

Universidad Euskal Herriko del País Vasco Unibertsitatea

\section{INTRODUCTION}

Subjective well-being is defined as the evaluation that a person makes about their situation at a given moment (Kuppens, Realo \& Diener, 2008), this evaluation includes both cognitive judgments and emotional reactions (Luhmann, Hawkley, Eid \& Cacioppo, 2012).

The cognitive component is a global assessment of the life trajectory carried out at a given time. The emotional component consists of two elements: positive affect (PA) and negative affect (NA), which reflect the emotional state at a given moment (Larsen, 2009).

\section{OBJECTIVE}

The objective of this paper was to examine the factor structure,

internal consistency and concurrent validity of the Chilean version of the PNA-10.

\section{METHOD}

\section{Participants}

421 young chileans between 12 and 17 years old $(M=14.55, S D=1.62), 215$ girls $(51,1 \%)$ and 206 boys $(48,9 \%)$.

\section{Procedure}

$\checkmark$ Approval was received by the ethics committee of Catholic University of the North, Chile; and ratified by ethics committee of the University of the Basque Country, Spain.

$\checkmark$ Contact was made with different educational establishments in Chile, through which the custodian progenitors of the young participants were acceded (signing an informed consent).

\section{Variables Measured and Instruments Used} Positive and Negative Affect was measured with the Brief Scale to Evaluate Positive and Negative Affect (PNA-10, Yárnoz-Yaben, Comino, \& Sansinenea, 2014), validated in Chile for youth population by Tay-Karapas, and Yárnoz-Yaben (2019).

Attachment was measured with the Parent and Peer Attachment Inventory (IPPA, Pace, San Martini, \& Zavattini, 2011), adapted and validated in Chile for the youth population by Tay-Karapas, and Yárnoz-Yaben (2018).

Self-esteem was measured with the Rosenberg Self-Esteem Scale (Rosenberg, 1965), validated in Chile for youth and adult population by RojasBarahona, Zegers, and Förster (2009).

Life satisfaction was measured with the Life Satisfaction Scale (SWLS, Diener, Emmons, Larsen, \& Griffin, 1985, Spanish adaptation Atienza, Pons, Balaguer, \& García-Merita, 2000), validated in Chile for the youth population by Tay-Karapas, and Yárnoz-Yaben (2019).

\section{RESULTS}

Results from our confirmatory analysis corroborate the two-dimensional factorial structure of the scale.

$\checkmark$ Internal consistency indices were adequate, $a=.86$ (PA) and $a=.79$ (NA)

$\checkmark$ Regarding concurrent validity, statistically significant associations were found between PA and NA, and attachment, self-esteem, and life satisfaction.

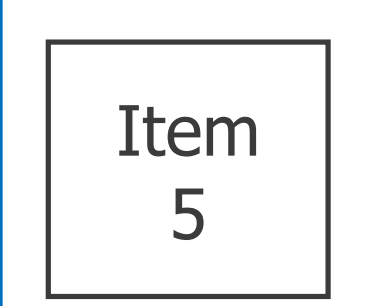

$\uparrow$

$78 * *$
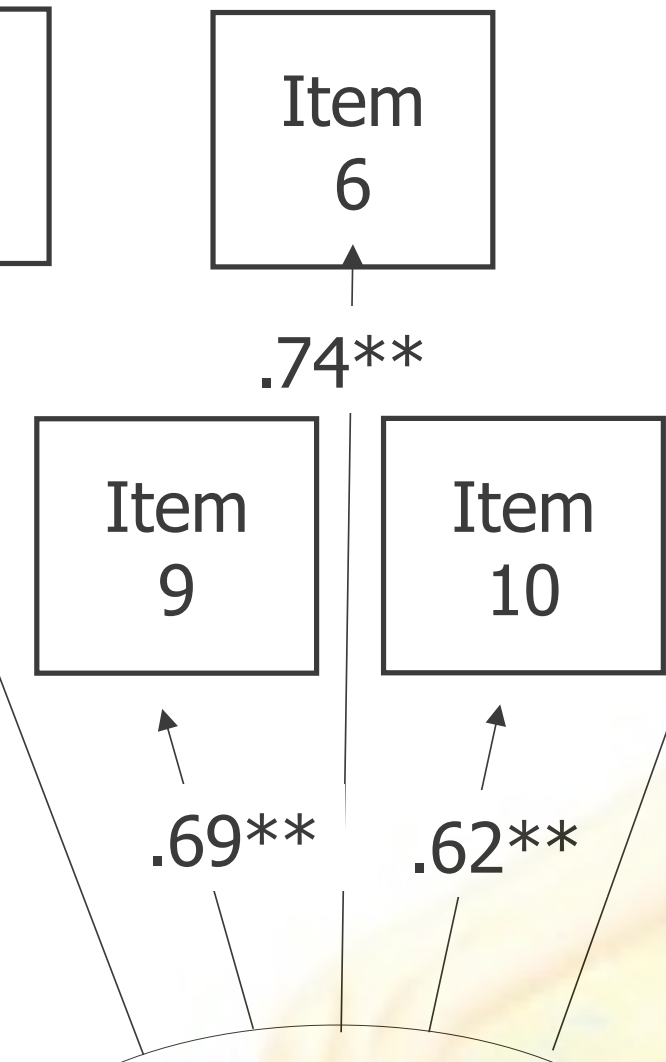

Positive Affect

$$
\alpha=.86
$$

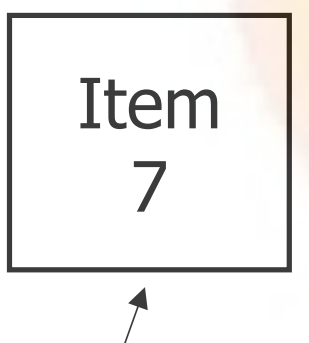

$.87 * *$

$$
\text { (1) }
$$

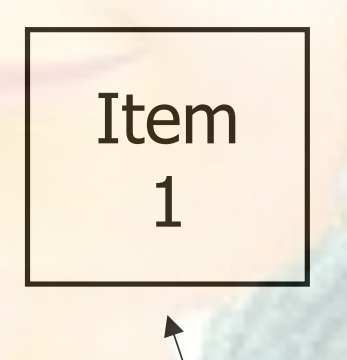

$.76 * *$

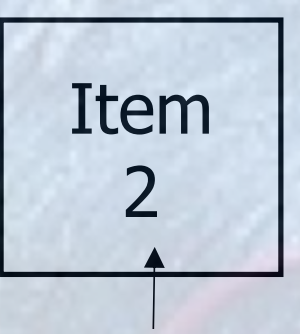

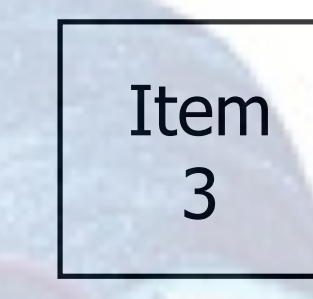

3
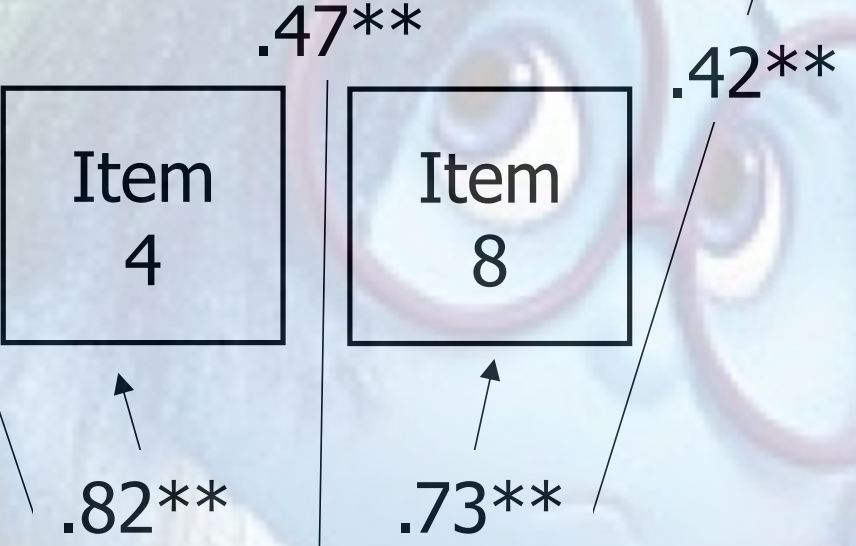

$73 * *$

\section{Negative Affect}

$\alpha=.79$

.

